\title{
Papers
}

\section{Fine needle aspiration cytology in the investigation of non-Hodgkin's lymphoma}

\author{
M D Jeffers, J Milton, R Herriot, M McKean
}

\begin{abstract}
Aims-To assess the value of flow cytometry (FCM) in the diagnosis and classification of reactive lymphoid hyperplasia and malignant lymphoma by fine needle aspiration (FNA) cytology.

Methods-Forty six fine needle aspirates of lymphoproliferative disorders were examined by FCM as well as routine cytological assessment. An immunoglobulin light chain ratio (LCR) was calculated for clonality analysis. Additional immunophenotyping was performed in 15 cases. Results-All 25 cases of reactive lymphoid hyperplasia were polyclonal by FCM (LCR < 2/1); 17 of 20 cases of $B$ cell non-Hodgkin's lymphoma were monoclonal (LCR > 3/1). Analysis of cells based on size facilitated detection of small populations of clonal neoplastic cells. Analysis of CD5, CD10, and CD23 expression by FCM facilitated subclassification of mantle cell lymphoma, small lymphocytic lymphoma, and some lymphomas of follicle centre cell origin. One case of $T$ cell non-Hodgkin's lymphoma was correctly classified by FCM.

Conclusions-FNA cytology is a reliable method for investigation of lymphoproliferative disorders. Although excision biopsy and histopathological examination remain the gold standard for primary diagnosis and classification of nonHodgkin's lymphoma, FNA cytology with clonality analysis and immunophenotyping by FCM is useful for distinguishing reactive from neoplastic lymphoid populations, and can facilitate lymphoma classification.

(F Clin Pathol 1998;51:189-196)
\end{abstract}

Keywords: lymphoma; fine needle aspiration cytology; flow cytometry; immunocytochemistry; non-Hodgkin's lymphoma

Fine needle aspiration (FNA) cytology is widely used in the investigation of lymphadenopathy, and offers immediate preliminary diagnosis with minimal trauma to the patient at considerably lower cost than surgical biopsy. ${ }^{12}$ FNA cytology is particularly useful in the diagnosis of metastatic malignancy in lymph nodes $^{34}$ and in the diagnosis of reactive lymphoid hyperplasia, ${ }^{4}$ but there is not, as yet, general agreement on the role of FNA cytology in the diagnosis and classification of malignant lymphoma, particularly low grade non-Hodgkin's lymphoma. ${ }^{235-7}$ In certain circumstances cytology preparations may be the only material available for diagnosis of malignant lymphoma, ${ }^{8}$ and it is important, therefore, to maximise the diagnostic yield and accuracy of cytopathology in the evaluation of lymphoid populations. ${ }^{9}$ Furthermore, with the recent increase in our understanding of the molecular genetic basis of many malignant lymphomas, FNA cytology can be particularly useful as a minimally invasive method to obtain samples of fresh cells suitable for cytogenetic analysis.

With the application of ancillary techniques, particularly immunocytochemistry, the reliability of cytological diagnosis of malignant lymphoma is greatly improved..$^{70-17}$ There are, however, both theoretical and technical limitations on the application of immunocytochemistry to cytological material, and alternative techniques $^{61011}{ }^{18-27}$ have been applied to material obtained by FNA cytology in an attempt to improve further the accuracy of diagnosis of lymphoproliferative disorders by cytopathology.

We describe our experience in the use of immunophenotyping by flow cytometry (FCM) as an ancillary technique in the evaluation of lymph node samples obtained by FNA, particularly the evaluation of immunoglobulin light chain expression, but also the expression of other markers relevant to the classification of malignant lymphoma.

\section{Materials and methods}

Forty six fine needle aspirates obtained over 11 months (40 percutaneous lymph node FNAs, one breast lump FNA, one chest wall mass FNA, one FNA of an abdominal mass, and three FNAs of fresh surgical biopsy specimens) where the diagnosis based on morphology was either reactive lymphoid hyperplasia, nonHodgkin's lymphoma, or suspicious of nonHodgkin's lymphoma, were studied. Cases of metastatic non-lymphoid malignant disease and cases of Hodgkin's disease were excluded. FNA was performed by a standard technique using a 23 gauge needle and a $10 \mathrm{ml}$ syringe 
Table 1 Results of flow cytometry (FCM) and biopsy in cases of reactive hyperplasia

\begin{tabular}{|c|c|c|c|c|c|c|}
\hline Case & Age/sex & Sample/site & Morphology & CD3 (\%) & $\begin{array}{l}\text { FCM k:l } \\
\text { ratio }\end{array}$ & Biopsy \\
\hline 1 & $50 / \mathrm{F}$ & Neck node & Reactive & 26.3 & $1.1: 1$ & ND \\
\hline 2 & $77 / \mathrm{F}$ & Axillary node & Reactive & 9.6 & $1.1: 1$ & $\mathrm{ND}$ \\
\hline 3 & $39 / \mathrm{M}$ & Neck node & Reactive & 26.8 & $1.3: 1$ & ND \\
\hline 4 & $30 / \mathrm{F}$ & Axillary node & Reactive (?necrosis) & 5.8 & $1: 1.0$ & Kikuchi's disease \\
\hline 5 & $65 / \mathrm{F}$ & Neck node & Reactive & 19.3 & $1: 1.0$ & ND \\
\hline 6 & $36 / \mathrm{F}$ & Neck node & Reactive & 18.7 & $1.1: 1$ & ND \\
\hline 7 & $9 / \mathrm{F}$ & Neck node & Reactive & 10.4 & $1.2: 1$ & ND \\
\hline 8 & $60 / \mathrm{M}$ & Neck node & Reactive & 30 & $1.2: 1$ & ND \\
\hline 9 & $63 / \mathrm{M}$ & Neck node & Reactive & 23.7 & $1.3: 1$ & ND \\
\hline 10 & $19 / \mathrm{F}$ & Submandibular & Reactive & 13.2 & $1.3: 1$ & ND \\
\hline 11 & $46 / \mathrm{F}$ & Neck node & Reactive & 7.7 & $1.4: 1$ & ND \\
\hline 12 & $7 / \mathrm{F}$ & Submandibular & Reactive & 6 & $0.8: 1$ & ND \\
\hline 13 & $38 / \mathrm{M}$ & Neck node & Reactive & 6.8 & $1.4: 1$ & ND \\
\hline 14 & $64 / \mathrm{F}$ & Neck node & Reactive & 3.9 & $1.4: 1$ & ND \\
\hline 15 & $35 / M$ & Axillary node & Reactive & 27.4 & $1: 0.6$ & ND \\
\hline 16 & $9 / \mathrm{F}$ & Neck node & Reactive & 10.9 & $1: 1.0$ & ND \\
\hline 17 & $41 / \mathrm{F}$ & Axillary node & Reactive & 18.7 & $1.1: 1$ & $\mathrm{ND}$ \\
\hline 18 & $21 / \mathrm{M}$ & Tonsil (fresh specimen) & Reactive & 12 & $1.1: 1$ & Reactive \\
\hline 19 & $58 / \mathrm{F}$ & Neck node & Reactive & 15.9 & $1.4: 1$ & ND \\
\hline 20 & $56 / \mathrm{F}$ & Neck node & Reactive & 25 & $1.2: 1$ & ND \\
\hline 21 & $49 / \mathrm{F}$ & Axillary node (fresh specimen) & Reactive & 9.1 & $1.4: 1$ & Reactive \\
\hline 22 & $31 / \mathrm{F}$ & Neck node & Reactive & 12.7 & 1.3:1 & Kikuchi's disease \\
\hline 23 & $36 / \mathrm{F}$ & Neck node & Reactive & 16.8 & $1.8: 1$ & ND \\
\hline 24 & $57 / \mathrm{F}$ & Neck node & Reactive & 7.7 & $1.1: 1$ & $\mathrm{ND}$ \\
\hline 25 & $32 / \mathrm{F}$ & Neck node & Reactive & 14.4 & $1.3: 1$ & ND \\
\hline
\end{tabular}

k:1, kappa:lambda.

with suction. Direct smears were prepared and allowed to air dry; they were stained with a Diff-Quik method, and one smear was fixed with alcohol and stained by the Papanicolau method. The needle was then rinsed in $10 \mathrm{ml}$ of saline to produce a suspension of cells for FCM.

MORPHOLOGY

A preliminary morphological diagnosis was made and, in cases of non-Hodgkin's lymphoma, subclassification was attempted using the Kiel classification system, or a REAL classification category if this was appropriate (for example, mantle zone lymphoma).

FLOW CYTOMETRY

The specimen was transferred to a conical tube and centrifuged at $400 \times g$ for five minutes. The supernatant was discarded and the pellet resuspended in $0.83 \% \mathrm{NH}_{4} \mathrm{Cl}$ red cell lysing buffer for 20 minutes. The specimen was centrifuged again at $400 \times g$ for five minutes and the pellet was suspended in 1-2 $\mathrm{ml}$ of RPMI with $10 \%$ fetal calf serum. A $50 \mu \mathrm{l}$ aliquot of the cell suspension was used for each antibody in the flow cytometric panel. The aliquot was combined with $5 \mu \mathrm{l}$ of antibody for 40 minutes in the dark at room temperature, and then washed once in PBS containing $0.1 \%$ sodium azide and resuspended to a volume of $1 \mathrm{ml}$. Flow cytometric analysis was performed on an Ortho Cytron Absolute Flow Cytometer using Immunocount software. An average of 3000 gated cells were analysed.

An initial panel of fluorochrome labelled antibodies was used: isotype and fluorochrome (fluorescein isothiocyanate (FITC), phycoerythrin (PE)) matched controls, HLA-DR (PE), CD3 (FITC), CD19 (FITC), kappa (PE), and lambda (PE). Dual staining was performed for CD3/HLA-DR, CD19/kappa, and CD19/lambda. If a diagnosis of non-Hodgkin's lymphoma was expected clinically or on the basis of cytomorphology, an additional panel including CD5 (FITC), CD10 (FITC), and CD23 (PE), all dual stained with CD19, was performed if sufficient material was available. All antibodies were obtained from Dako Ltd (High Wycombe, Bucks, UK).

In one case, the suspected diagnosis on the basis of morphology and clinical findings was $\mathrm{T}$ cell non-Hodgkin's lymphoma, and in this case a different panel was performed: CD2, CD3, CD4, CD7, CD8, and dual CD3/CD8 and
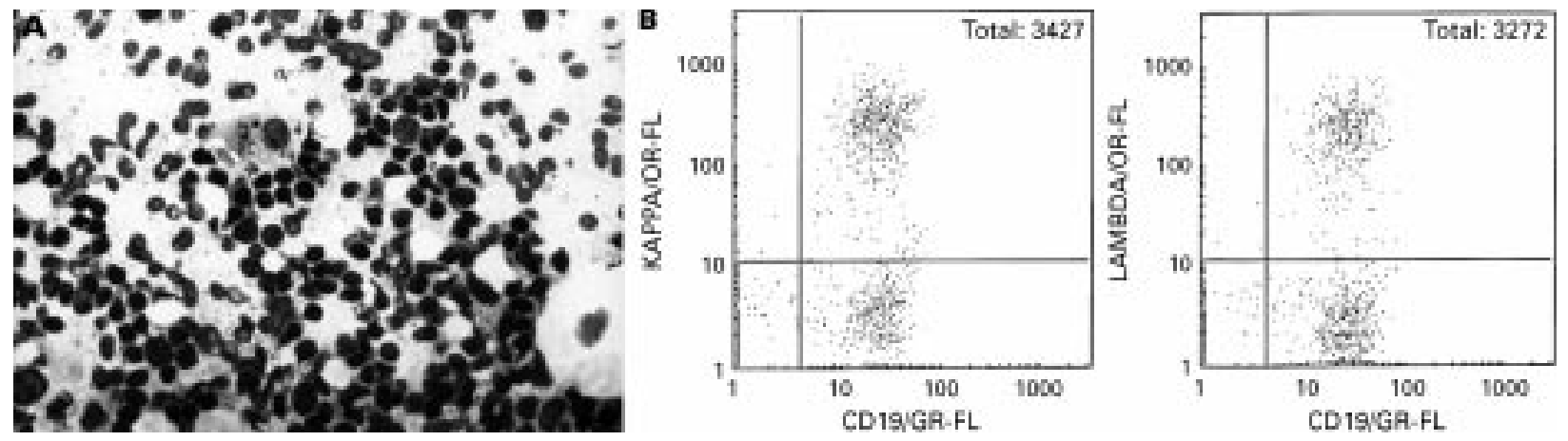

Figure 1 Reactive hyperplasia (case 21; female, 58 years old), FNA of cervical node. (A) A polymorphic population of lymphoid cells and occasional histiocytes (direct smear, Diff-Quik). (B) Flow cytometry: 22\% CD19+/kappa+, 16\% CD19+/lambda+, LCR, 1.4:1. 
Table 2 Morphology, flow cytometry (FCM), and biopsy in cases of non-Hodgkin's lymphoma (NHL)

\begin{tabular}{|c|c|c|c|c|}
\hline Case & Cytological diagnosis & FCM k:l ratio & Final diagnosis & Biopsy \\
\hline 1 & Low grade NHL & $1: 170$ & Low grade $\mathrm{B}$ cell NHL/FCC & Malignant lymphoma follicular, centrocytic \\
\hline 2 & Low grade NHL & $1: 29$ & Low grade $\mathrm{B}$ cell $\mathrm{NHL} / \mathrm{FCC}$ & Malignant lymphoma follicular, centroblastic-centrocytic \\
\hline 3 & Low grade NHL & $5: 1(10: 1)$ & Low grade $\mathrm{B}$ cell NHL/FCC & $\begin{array}{l}\text { Malignant lymphoma, MALT, small bowel with nodal } \\
\text { involvement }\end{array}$ \\
\hline 4 & Low grade NHL & $18: 1$ & Low grade $\mathrm{B}$ cell NHL/FCC & Malignant lymphoma follicular, cenroblastic-centrocytic ${ }^{\star}$ \\
\hline 5 & Suspicious of low grade NHL & $14: 1$ & Low grade $\mathrm{B}$ cell $\mathrm{NHL} / \mathrm{FCC}$ & Malignant lymphoma follicular, cenroblastic-centrocytic \\
\hline 6 & Suspicious of low grade NHL & $18: 1$ & Low grade $\mathrm{B}$ cell NHL/FCC & Malignant lymphoma follicular, centrocytic ${ }^{\star}$ \\
\hline 7 & Suspicious of low grade NHL & $1: 4(1: 4)$ & Low grade $\mathrm{B}$ cell NHL/FCC & Malignant lymphoma follicular, cenroblastic-centrocytic \\
\hline 8 & Low grade NHL & $60: 1$ & Low grade $\mathrm{B}$ cell NHL & Not done \\
\hline 9 & Large cell NHL & $19: 1(43: 1)$ & Large cell B cell lymphoma & Malignant lymphoma, centroblastic \\
\hline 10 & Large cell NHL & $1: 8(1: 82)$ & Large cell B cell lymphoma & Malignant lymphoma, centroblastic \\
\hline 11 & Large cell NHL & $4: 1(33: 1)$ & Large cell B cell lymphoma & Not done \\
\hline 12 & Large cell NHL & $5: 1(22: 1)$ & Large cell B cell lymphoma & Malignant lymphoma, large B cell ${ }^{\star}$ \\
\hline 13 & Suspicious of large cell NHL & $1.4: 1(1: 3.5$ & Suspicious of large cell B cell lymphoma & Malignant lymphoma, $\mathrm{T}$ cell rich B cell lymphoma \\
\hline 14 & Low grade NHL, ?MCL & $18: 1$ & MCL & Malignant lymphoma, mantle cell \\
\hline 15 & Low grade NHL, ?MCL & $160: 1$ & MCL & Malignant lymphoma, mantle cell ${ }^{\star}$ \\
\hline 16 & Low grade NHL & Uninterpretable & Low grade NHL, ?MCL & Malignant lymphoma, mantle cell \\
\hline 17 & Low grade NHL, ?SLL & $8: 1$ & Small lymphocytic lymphoma & Malignant lymphoma, small lymphocytic \\
\hline 18 & Low grade NHL & 109:1 & Small lymphocytic lymphoma & Malignant lymphoma, small lymphocytic \\
\hline 19 & Suspicious of low grade NHL & $1: 1.1(1: 1.6)$ & Suspicious of low grade NHL & Malignant lymphoma follicular, cenroblastic-centrocytic ${ }^{\star}$ \\
\hline 20 & Suspicious of low grade NHL & $0.8: 1$ & Suspicious of low grade NHL & Malignant lymphoma follicular, cenroblastic-centrocytic \\
\hline
\end{tabular}

${ }^{\star}$ Diagnosis of NHL known from previous biopsies.

k:l, kappa:lambda; MCL, mantle cell lymphoma; SLL, small lymphocytic lymphoma; FCC, consistent with follicle centre cell origin.

\section{$\mathrm{CD} 3 / \mathrm{CD} 4$.}

It became apparent early in the study that populations of large cells were present in cases of non-Hodgkin's lymphoma that fell outside the standard software generated "lymphocyte" gate normally used for analysis of lymphocytes. In these cases, a second gate was analysed that included these populations of larger cells.

In cases of reactive hyperplasia and suspected B cell non-Hodgkin's lymphoma, a light chain ratio (LCR) was calculated based on the ratio of the greater to the lesser immunoglobulin light chain.

CYTOGENETICS

In one case, material from the cell suspension was submitted for cytogenetic analysis.

CYTOLOGY-HISTOLOGY CORRELATION

Where available, current or previous lymph node biopsies were reviewed and the results of FNA cytology and histopathology were compared.

\section{Results}

On the basis of cytological examination of the direct smears alone, 25 cases were diagnosed as reactive hyperplasia, 20 as non-Hodgkin's lymphoma or suspicious of non-Hodgkin's lymphoma, and one as probable $\mathrm{T}$ cell non-Hodgkin's lymphoma.

REACTIVE HYPERPLASIA

The cases were 17 cervical/supraclavicular nodes, five axillary nodes, two submandibular nodes, and one FNA of a fresh tonsillectomy specimen. Eighteen patients were female (age range 9-77 years) and seven were male (age range 7-63 years). The results of FCM and biopsy are shown in table 1 .

The range of LCRs by FCM was 1:0.6 to 1.8:1. No case had a light chain ratio $>1.8: 1$. The results of light chain expression analysis by FCM correlated well with alkaline phosphatase antialkaline phosphatase (APAAP) immunocytochemistry for kappa and lambda light chain, which was performed in seven cases (data not shown). The proportion of activated $\mathrm{T}$ cells (CD3+/HLA-DR+) present ranged from 3.9\% to $30 \%$.

Biopsy specimens were available in four cases; in two cases reactive hyperplasia was confirmed and two cases were reported as Kikuchi's disease. Figure 1 shows an example of reactive hyperplasia.

NON-HODGKIN'S LYMPHOMA/SUSPICIOUS OF NON-HODGKIN'S LYMPHOMA

The 20 cases were 11 cervical/supraclavicular
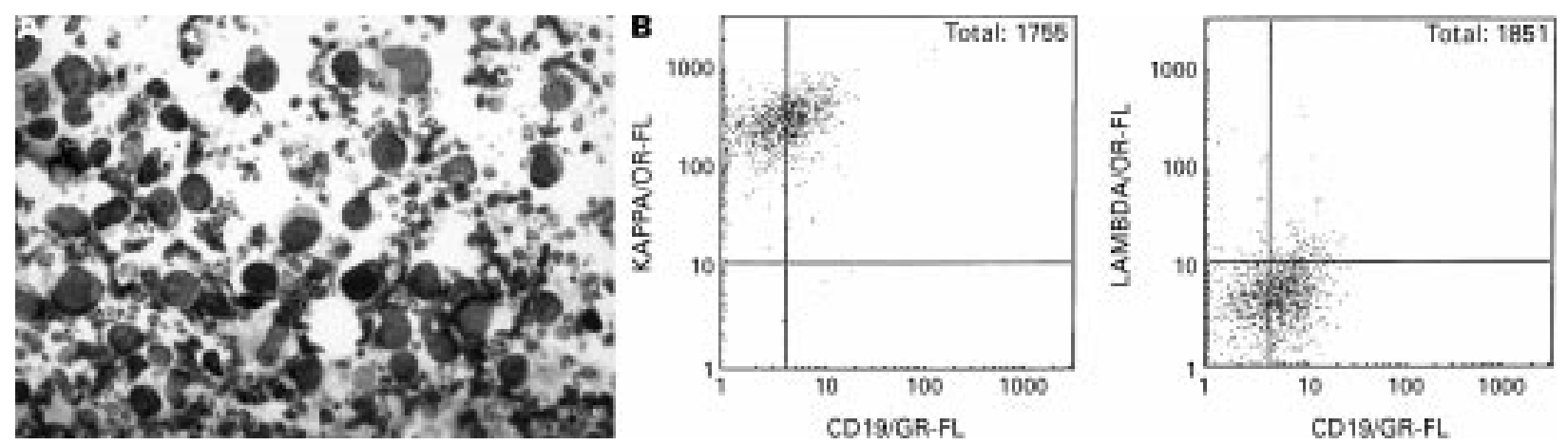

Figure 2 Non-Hodgkin's lymphoma (case 12; female, 39 years); large B cell non-Hodgkin's lymphoma, FNA of supraclavicular node. (A) $A$ monomorphic population of large lymphoid cells characteristic of large cell non-Hodgkin's lymphoma (direct smear, Diff-Quik). (B) Flow cytometry (gated for large cells): $37 \%$ CD19+/kappa+, $1.7 \%$ CD19+/lambda+, LCR, 22:1. 

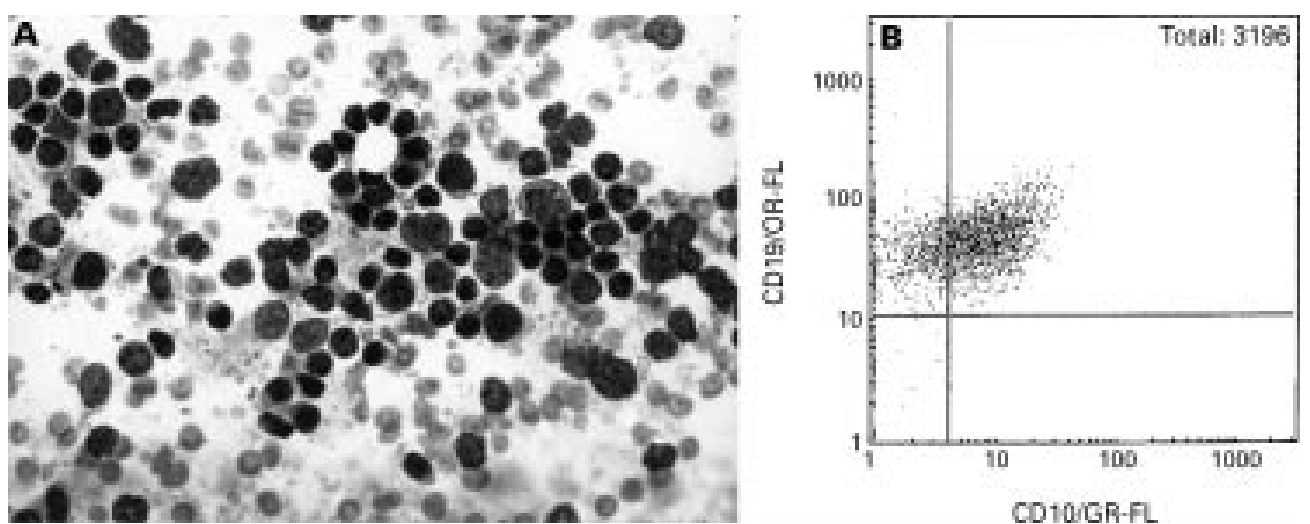

Figure 3 Non-Hodgkin's lymphoma (case 6; female, 80 years); low grade non-Hodgkin's lymphoma, FCC origin, LCR, 18:1, FNA of cervical node. (A) Monomorphic population of intermediate sized cells and occasional larger cells, no histiocytes (direct smear, Diff-Quik). (B) Flow cytometry: 51\% CD19+/CD10+.

nodes, two axillary nodes, three groin nodes,one breast lump, one chest wall mass, and two FNAs of fresh surgical lymph node excision biopsy specimens. Eight patients were female (age range 39-80 years) and 12 were male (age range 33-85). Five patients had had a previous diagnosis of B cell non-Hodgkin's lymphoma and had presented with recurrent lymphadenopathy. Table 2 shows the initial morphological diagnosis, results of FCM, final diagnosis based on combination of cytomorphology and FCM, and histological diagnosis. Figures 2-5 are representative examples.

The range of LCRs by FCM was $1: 0.8$ to 170:1. The LCR was $>6: 1$ in 12 cases on the standard lymphocyte gate. In two of these 12 cases, analysis of the large cell gate revealed a significantly greater LCR (19:1 increased to $43: 1$, case 9 ; and $1: 8$ to $1: 82$, case 10 ).

In four cases, the LCR on the standard lymphocyte gate was $>3: 1$ but $<6: 1$. In three of these four cases the large cell gate revealed a significantly greater LCR (4:1 increased to $33: 1$, case $11 ; 5: 1$ to $22: 1$, case $12 ; 5: 1$ to $10: 1$, case 3 ). In case 7 , both large cell gate analysis and flow cytometric analysis of fresh tissue from the subsequent lymph node excision biopsy failed to yield a higher LCR despite histological confirmation of the diagnosis of malignant lymphoma.

In three cases, the LCR of the standard gate was $<3: 1$. In one of these cases (case 13), the large cell gate revealed a population of cells with kappa:lambda ratio $1: 3.5$. In the remaining two cases, no significant evidence of monoclonality could be demonstrated on the basis of LCR. In case 19, large cell gate analysis also failed to demonstrate a monoclonal LCR despite subsequent histological confirmation of malignant lymphoma. The other case (case 20) was the first performed in the study, at which time large cell gate analysis was not performed. In one case the results of FCM were uninterpretable because of non-specific antibody binding.

In summary, 15 of 20 cases had an LCR $>6: 1,12$ on standard gate and three on analysis of the large cell gate. Seventeen of 20 cases had an LCR of $>3: 1,16$ on standard gate and one on analysis of the large cell gate. Of the two cases with LCRs $<3: 1$, one did not have large cell gate analysis performed and one is unexplained. APAAP immunocytochemistry for immunoglobulin light chains correlated well with FCM in 10 cases and was equivocal or uninterpretable in three (data not shown).

The proportion of activated $\mathrm{T}$ cells (dual CD3+/HLA-DR+) varied from $2.3 \%$ to $59.3 \%$. In two cases of large B cell lymphoma (cases 9 and 10) substantially fewer $\mathrm{T}$ cells were present in the large cell region than in the
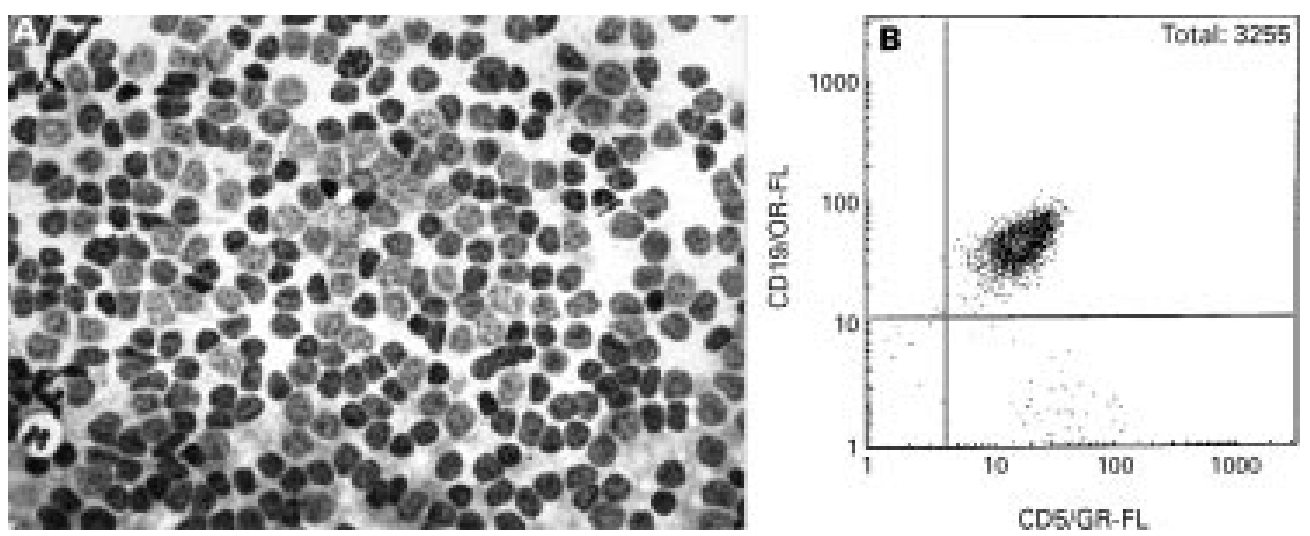

Figure 4 Non-Hodgkin's lymphoma (case 14; male 73 years); mantle cell lymphoma, LCR, 18:1, FNA cervical node. (A) Monomorphic population of lymphoid cells, some with angulated nuclei, no blast cells (direct smear, Diff-Quik). (B) Flow cytometry: 96\% CD19+/CD5+. 

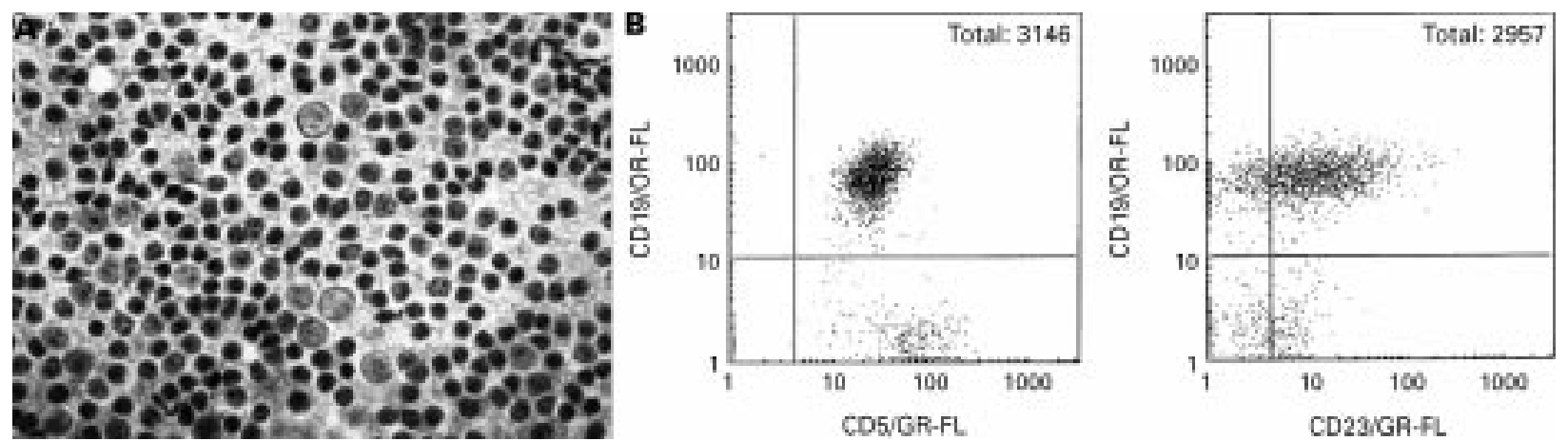

Figure 5 Non-Hodgkin's lymphoma (case 17; male, 70 years); small lymphocytic lymphoma, LCR, 8:1, FNA cervical node. ( $A$ ) Monomorphic population of small lymphoid cells, occasional larger cells (para-immunoblasts) (direct smear, Diff-Quik). (B) Flow cytometry: 82\% CD19+/CD5+, 64\% $C D 19+/ C D 23+$

standard lymphocyte gate, and in both of thesecases the large cell region also revealed a substantially greater LCR than the standard gate. In one case, subsequently reported histologically as $\mathrm{T}$ cell rich B cell lymphoma (case 13), significant numbers of $T$ cells persisted in the large cell region.

Additional immunophenotyping using antibodies to CD5, CD10, and CD23, all dual stained with CD19, was attempted in 15 cases. Five cases (three low grade non-Hodgkin's lymphoma, cases 2, 3, and 7; and two large B cell lymphoma, cases 9 and 10), contained a significant proportion of CD10+ B cells (range $27-68 \%$ ) by FCM, favouring a follicle centre cell origin for these tumours. This CD10 expression was specifically identified in the large cell region in three of the five cases. Immunocytochemistry for CD10 was negative in all five cases. One case (case 3), which contained $<20 \%$ CD10+ cells, was interpreted as LGB non-Hodgkin's lymphoma, possibly of FCC origin, but was demonstrated on biopsy to be nodal involvement by a MALT-type lymphoma of the small intestine.

Two cases (cases 14 and 15) contained B cells that were mostly CD5+ (>90\%), CD10-, CD23- by FCM, favouring a diagnosis of mantle cell lymphoma. CD5 immunocytochemistry was strongly positive in case 16 with negative CD10 and CD23, supporting a diagnosis of mantle cell lymphoma (FCM was uninterpretable because of non-specific antibody binding in this case).

Two cases (cases 17 and 18) contained $\mathrm{B}$ cells that were mostly CD5+, CD10-, CD23+, favouring a diagnosis of small lymphocytic lymphoma (ML-SLL). Cytogenetic analysis was also performed on material obtained by FNA in one case revealing trisomy 12, consistent with the diagnosis of ML-SLL

Additional immunophenotyping was noncontributory in the remaining six cases.

T CELL LYMPHOMA

An ultrasound guided FNA of an abdominal mass in a 58 year old man was suspected on the basis of morphology and clinical background to be a $\mathrm{T}$ cell non-Hodgkin's lymphoma. Most cells were $\mathrm{CD} 2+, \mathrm{CD} 3+, \mathrm{CD} 7+, \mathrm{CD} 3+$ / $\mathrm{CD} 8+, \mathrm{CD} 3+/ \mathrm{CD} 4-$, supporting a diagnosis of $\mathrm{T}$ cell non-Hodgkin's lymphoma. Biopsy and subsequent small bowel resection confirmed the diagnosis of small intestinal $\mathrm{T}$ cell non-Hodgkin's lymphoma (not associated with enteropathy).

\section{Discussion}

FNA cytology has a proven role in the diagnosis of metastatic non-lymphoid malignancies in lymph nodes, ${ }^{1}$ but there has been reluctance to accept FNA cytology in the investigation or diagnosis of lymphoproliferative disorders, largely because of potential problems associated with partial lymph node involvement, the loss of architectural criteria in material obtained by aspiration, the inherent difficulties in interpretation of mixed lymphoid populations that characterise many low grade malignant lymphomas, and the possibility of overlooking small numbers of neoplastic cells masked by a dominant reactive population. .7 $^{-7428} 29$ Excision biopsy and histopathological diagnosis remain the gold standard for the diagnosis of malignant lymphoma in most centres. With the application of immunocytochemistry to cytological material, the diagnostic accuracy of cytopathology is significantly increased, ${ }^{13}$ and is equivalent to that of histopathology in many series. ${ }^{15} 16^{30}$ Furthermore, cases that are difficult to diagnose or classify using cytology often present similar difficulties using histopathology. ${ }^{30-32}$ More widespread use of FNA cytology for diagnosis of malignant lymphoma is now advocated in certain circumstances, including the investigation of suspected recurrent disease in patients known to have malignant lymphoma, assessment of transformation to higher grade disease, determination of disease stage without a requirement for multiple biopsies, diagnosis in clinical situations where open biopsy is impractical, and as an initial method in the investigation of suspected lymphoma, followed by biopsy for complete work up. ${ }^{2-5} 783233$ Some authors go even further and suggest that FNA cytology is superior to biopsy in terms of preservation of cytological detail, minimal morbidity to the patient, and speed and low cost of the procedure ${ }^{4}$; and that FNA cytology in conjunction with immunophenotypic analysis is a reliable and accurate method for diagnosis and classification of most cases of lymphoma, ${ }^{11}$ and 
may replace biopsy for special studies. ${ }^{14}{ }^{15} \mathrm{It}$ has also been stated that "accurate cytology will make surgery superfluous in the diagnostic work up of patients with lymphoproliferative disorders." 9

Ancillary techniques are useful in the evaluation of lymph node aspirates in determination of cell lineage, in confirmation of clonality in B cell populations, and in characterisation of phenotype. The application of immunocytochemistry has greatly improved the accuracy of diagnosis and classification of malignant lymphomas in cytological material, and other techniques including immunophenotyping by FCM, ${ }^{61011} 192034$ and laser scanning cytometry, ${ }^{21}$ and molecular methods including immunoglobulin light chain mRNA detection by in situ hybridisation, ${ }^{22}$ and immunoglobulin heavy chain gene rearrangement analysis by Southern blotting, ${ }^{181928}$ and polymerase chain reaction, ${ }^{23-25}$ have also been demonstrated to be of value. In determination of clonality and further phenotypic analysis, FCM offers some advantages over immunocytochemistry in terms of speed, dual staining, quantitative analysis, and fewer problems with non-specific background staining. ${ }^{611}$ Excellent concordance between FCM and immunocytochemistry has been demonstrated in the evaluation of clonality $^{6}$ and, for practical purposes, it has been suggested that FCM is technically superior to immunocytochemistry in situations where the material can be provided in the form of a cell suspension. ${ }^{61120}$

Demonstration of monoclonality is strong supporting evidence of malignancy in lymphoid populations, ${ }^{81}$ although monoclonal immunoglobulin light chain expression has been documented in certain non-neoplastic circumstances including specific infections and autoimmune conditions. ${ }^{34}{ }^{35}$ There is some variation in published criteria for monoclonality in cytological material, and most authors require an LCR of $>6: 1$ by immunocytochemistry, and classification of cases with an LCR of $>3: 1$ but $<6: 1$ as atypical. ${ }^{1429}$ Quantitative analysis as offered by FCM is possibly superior to immunocytochemistry in this respect, and it has been suggested that an LCR of $>3: 1$ by FCM in a satisfactory specimen is adequate for the diagnosis of monoclonality in the context of supporting clinical and morphological evidence of lymphoma. ${ }^{411202936}$ With advances in understanding of molecular genetics and pathogenesis, additional criteria including more detailed immunophenotyping and, in some cases, genotyping, are becoming important in the classification of malignant lymphoma, as is evident in the more recent classification schemes proposed such as the revised European American lymphoma (REAL) classification. ${ }^{2137}$ Subclassification of low grade B cell non-Hodgkin's lymphoma may be difficult on the basis of morphology alone and, although immunophenotyping facilitates accurate diagnosis, some of the relevant antibodies are not, as yet, applicable to paraffin wax embedded biopsy material. These antibodies are readily applicable to immunocytochemistry on fresh material and to FCM, the latter offering the advantage of dual staining with $\mathrm{B}$ or $\mathrm{T}$ cell specific markers. There have been occasional reports of improved lymphoma diagnosis and classification using a combination of morphological examination and immunophenotyping by FCM and laser scanning cytometry of material obtained by FNA both in vitro and in clinical aspirates. $^{1117202127}$

In our series, FNA cytology diagnosis of lymphoproliferative disorders, using a combination of morphology and FCM, was accurate and correlated well with the eventual histopathological diagnosis. Reactive lymphoid hyperplasia was characterised in all cases by polyclonal expression of immunoglobulin light chains and the LCR was $<2: 1$ in all cases. A definitive diagnosis of malignant lymphoma by cytology was achieved in 17 of 20 cases of B cell non-Hodgkin's lymphoma based on an LCR of $>3: 1$. In most cases, the LCR was $>6: 1$, which is advocated by some as the minimum value for definitive diagnosis, but we believe that a ratio of $>3: 1$ by FCM in the context of appropriate morphological findings, is sufficient to diagnose malignancy. The LCR was $<3: 1$ in two cases of $\mathrm{B}$ cell non-Hodgkin's lymphoma: light chain expression was also examined by immunocytochemistry in one case and gave equivocal results. In both cases morphology was atypical and biopsy was advised. Such cases are probably neoplasms with low levels of expression of immunoglobulin light chains where firm evidence of clonality may not be possible on the basis of immunological methods, as previously described. ${ }^{14}$ These cases illustrate the importance of interpretation of ancillary techniques in conjunction with morphological and clinical information; a polyclonal pattern of light chain expression should be ignored if there is significant suspicion of malignancy based on atypical morphology.

One major advantage of FCM, which became apparent in the course of our study, is the ability to examine specific subpopulations within the sample based on cell size, using an approach broadly similar to the multiparameter analysis described by Witzig and colleagues ${ }^{20}$ and Zander and colleagues. ${ }^{11} \mathrm{By}$ selecting cell populations according to size, neoplastic clones can be identified that might otherwise be obscured by reactive $T$ cells or non-neoplastic B cells. This method revealed neoplastic populations of large cells with much higher LCR values than cells within the standard lymphocyte gate on FCM in several cases. In some of these cases, the diagnosis was already evident from the standard size gate, but in others, most notably a case of $\mathrm{T}$ cell rich B cell lymphoma, the neoplastic population would otherwise have been overlooked, particularly if a 6:1 threshold for LCR was applied.

In addition to providing clear, quantitative evidence of clonality, FCM can facilitate subclassification of lymphoma, particularly low grade B cell non-Hodgkin's lymphoma. Differential patterns of expression of CD5, CD10, and CD23 on neoplastic B cells can confirm 
the subtype of low grade B cell non-Hodgkin's lymphoma, a distinction that may be difficult on the basis of morphology alone. In two of our cases, expression of CD5 on the neoplastic B cells in the absence of CD10 and CD23 confirmed the diagnosis of mantle cell lymphoma. An advantage of FCM in this context is confirmation by dual staining of CD5 expression on B cells, which would not have been possible using standard immunocytochemical techniques. Similarly, in a case of small lymphocytic lymphoma, co-expression of CD5 and CD23 on neoplastic B cells confirmed the diagnosis. CD10 expression was useful in confirming a follicle centre cell origin in some cases, and FCM was superior to immunocytochemistry, which failed to demonstrate CD10 in any case. It is not clear why some cases of proven follicle centre cell lymphoma failed to mark with CD10, and this illustrates the importance of interpretation of marker studies in the context of the cytomorphological appearances. ${ }^{38}$ The panel of antibodies used in this study constitutes what is probably a cost-effective use of resources in relation to diagnosis in most cases. In difficult cases or where larger panels are desirable, additional antibodies against cellular antigens such as CD11c, CD25 or FMC-7 could be used either initially or as follow up for more detailed classification.

We encountered one case of $\mathrm{T}$ cell lymphoma that was correctly classified on the basis of a majority of T cells with CD8+ subset restriction (>90\% CD3+/CD8+).

In summary, we have shown that FNA cytology is a useful diagnostic method for the investigation of lymphoproliferative disorders and, in conjunction with FCM, provides accurate reliable diagnosis that correlates well with histopathology. Open biopsy can be avoided in cases of reactive hyperplasia, which are proven to be polyclonal, although if there is any doubt regarding either the morphology or the clinical context, follow up is recommended because, as has been noted previously, ${ }^{15}{ }^{29}$ polyclonality alone does not exclude the diagnosis of lymphoma, particularly Hodgkin's disease, but also occasional cases of B cell non-Hodgkin's lymphoma. Where FCM confirms monoclonality, a definitive diagnosis of nonHodgkin's lymphoma can be made and, in certain circumstances, an accurate subtype assigned on the basis of additional immunophenotypic information.

Excision biopsy and histopathological examination remain the gold standard for the primary diagnosis and classification of nonHodgkin's lymphoma. FNA cytology in conjunction with immunophenotypic analysis is a reliable method that can be used as a first line investigation to give rapid results, which can guide further investigation and facilitate costeffective patient management. Unnecessary biopsies can be avoided where a combination of clinical information, morphology, and immunophenotype indicate a reactive process, and where biopsy may be impractical or undesirable, as in the case of suspected recurrence of a previously diagnosed lymphoma.
1 Orell SR, Sterrett GF, Walters MN, et al. Lymph nodes. In: Manual and atlas of fine needle aspiration cytology. 2nd ed. Manual and atlas of fine needle aspiration cy

2 Tani EM, Christensson B, Porwit A, et al. Immunocytochemical analysis and cytomorphologic diagnosis on fine needle aspirates of lymphoproliferative disease. Acta Cytologica 1988;32:209-15.

3 Hanson CA. Fine needle aspiration and immunophenotyping. A role in diagnostic hematopathology? Am 7 Clin Pathol 1994;101:555-6.

4 Levitt S, Cheng L, DuPuis MH, et al. Fine needle aspiration diagnosis of malignant lymphoma with confirmation by immunoperoxidase staining. Acta Cytologica 1985;29:895imm

5 North L, Katz R, Carrasco H, et al. What is the role of fine needle biopsy in the diagnosis of lymphoma? Am $\mathcal{F}$ Radiol 1995;165:1299.

6 Robins DB, Katz RL, Swan F Jr, et al. Immunotyping of lymphoma by fine-needle aspiration. A comparative study of cytospin preparations and flow cytometry [see comments]. Am f Clin Pathol 1994;101:569-76.

7 Daskalopoulou D, Harhalakis N, Maouni N, et al. Fine needle aspiration cytology of non-Hodgkin's lymphomas. A morphologic and immunophenotypic study. Acta Cytologica 1995;39:180-6.

8 Leong ASY, Stevens M. Fine needle aspiration biopsy for the diagnosis of lymphoma: a perspective. Diagn Cytopathol 1996;15:352-7

9 Tani E, Skoog L. Being positive about negative cytology [editorial]. Diagn Cytopathol 1996;14:257-8

10 Steel BL, Schwartz MR, Ramzy I. Fine needle aspiration biopsy in the diagnosis of lymphadenopathy in 1,103 patients. Role, limitations and analysis of diagnostic pitfalls. Acta Cytologica 1995;39:76-81.

11 Zander DS, Iturraspe JA, Everett ET, et al. Flow cytometry. In vitro assessment of its potential application for diagnosis and classification of lymphoid processes in cytologic preparations from fine-needle aspirates. Am f Clin Pathol 1994;101:577-86.

12 Martin SE, Zhang H-Z, Magyarosy E, et al. Immunologic methods in cytology: definitive diagnosis of non-Hodgkins ymphomas using immunologic markers for T- and B-cells. Am 7 Clin Pathol 1984;82:666-73.

13 Cafferty LL, Katz RL, Ordonez NG, et al. Fine needle aspiration diagnosis of intraabdominal and retroperitoneal lymphomas by a morphologic and immunocytochemical lymphomas by a morphologic

14 Sneige N, Dekmezian RH, Katz RL, et al. Morphologic and immunocytochemical evaluation of 220 fine needle aspirates of malignant lymphoma and lymphoid hyperplasia. Acta Cytologica 1990;34:311-22.

15 Sneige N, Dekmezian R, El-Naggar A, et al. Cytomorphologic, immunocytochemical and nucleic acid flow cytometric study of 50 lymph nodes by fine needle aspiration. Cancer 1991;67:1003-7.

16 Tani E, Liliemark J, Svedmyr E, et al. Cytomorphology and immuncytochemistry of fine needle aspirates from blastic non-Hodgkin's lymphomas. Acta Cytologica 1989;33:36371 .

17 Wojcik EM, Katz RL, Fanning TV, et al. Diagnosis of mantle cell lymphoma on tissue acquired by fine needle aspiration in conjunction with immunocytochemistry and cytokinetic studies. Acta Cytologica 1995;39:909-15.

18 Cartagena N Jr, Katz RL, Hirsch-Ginsberg C, et al. Accuracy of diagnosis of malignant lymphoma by combining fine-needle aspiration cytomorphology with immunocytochemistry and in selected cases, Southern blotting of aspirated cells: a tissue-controlled study of 86 patients. Diagn Cytopathol 1992;8:456-64.

19 Galindo LM, Havlioglu N, Grosso LE. Cytologic findings in a case of T-cell rich B-cell lymphoma: potential diagnostic pitfall in FNA of lymph nodes. Diagn Cytopathol 1996;14: pitfall 7 .

20 Witzig TE, Banks PM, Stenson MJ, et al. Rapid immunophenotyping of B-cell non-Hodgkins lymphomas by flow cytometry. Am f Clin Pathol 1990;94:280-6.

21 Clatch R, Walloch JL. Multiparameter immunophenotypic analysis of fine needle aspiration biopsies and other hematologic specimens by laser scanning cytometry. Acta Cytologica 1997;41:109-22.

22 Stewart CJR, Farquharson MA, Kerr T, et al. Immunoglobulin light chain mRNA detected by in situ hybridisation in diagnostic fine needle aspiration cytology specimens. F Clin Pathol 1996;49:749-54.

23 Jeffers MD, McCorriston J, Farquharson M, et al. Analysis of clonality in cytologic material using the polymerase chain reaction. Cytopathology. [In press.]

24 Chan WC, Greiner TC. Diagnosis of lymphomas by the polymerase chain reaction [editorial]. Am $\mathcal{f}$ Clin Pathol 994;102:273-4.

25 Wan JH, Sykes PJ, Orell SR, et al. Rapid method for detecting monoclonality in B cell lymphoma in lymph node aspirates using the polymerase chain reaction. F Clin Pathol 1992;45:420-3

26 Katz RL, Hirsch-Ginsberg C, Childs C. The role of gene rearrangements for antigen receptors in the diagnosis of lymphoma obtained by fine needle aspiration. Am $\mathcal{F} \mathrm{Clin}$ Pathol 1991;96:479-90.

27 Saddik M, El Dabbagh L, Mourad WA. Ex vivo fine needle aspiration cytology and flow cytometric phenotyping in the diagnosis of lymphoproliferative disorders. Diagn Cytopathol 1997;16:126-31. 
28 Hajdu SI, Melamed MR. Limitations of aspiration cytology in the diagnosis of primary neoplasms. Acta Cytologica 1984;28:337-45.

29 Sneige N. Diagnosis of lymphoma and reactive lymphoid hyperplasia by immunocytochemical analysis of fine needle aspiration biopsy. Diagn Cytopathol 1990;6:39-43.

30 Carter TR, Feldman PS, Innes DJ, et al. The role of fine needle aspiration cytology in the diagnosis of lymphoma. Acta Cytologica 1988;32:848-53

31 Das DK, Gupta SK, Datta BN, et al. FNA cytodiagnosis of non-Hodgkin's lymphoma and its subtyping under working formulation of 175 cases. Diagn Cytopathol 1991;7:487-98.

32 Pontifex AH, Klimo P. Application of aspiration biopsy cytology to lymphomas. Cancer 1984;53:553-6.

33 Russell J, Skinner J, Orell S, et al. Fine needle aspiration in the management of lymphoma. Aust NZ F Med 1983;13: 365-8.
34 Levy N, Nelson J, Meyer P, et al. Reactive lymphoid hyperplasia with single class (monoclonal) surface immuplasia with single class (monoclonal) su

35 Patluke M, Schnitzer B, Mirchandani I, et al. Increased numbers of lymphocytes with single class surface immunoglobulin in reactive hyperplasia of lymphoid tissue. $\mathrm{Am} \mathcal{F}$ Clin Pathol 1982;78:316-23.

36 Geary WA, Frierson HF, Innes DJ, et al. Quantitative criteia for clonality in the diagnosis of B cell non Hodgkin's lymphoma by flow cytometry. Mod Pathol 1993;6:155-61.

37 Chan JKC, Banks PM, Cleary ML, et al. A proposal for classification of lymphoid neoplasms (by the International Lymphoma Study Group). Histopathology 1994;25:51736.

38 Sewell HF, Milton JI, MacKenzie R, et al. Immunophenotyping of leukemias by flow cytometry and APAAP: a twoyear comparative analysis in hospital practice. Disease Markers 1988;6:221-9. 